Journal of Current and Advance Medical Research

January 2019, Vol. 6, No. 1, pp. 28-31

http://www.banglajol.info/index.php/JCAMR

ISSN (Print) 2313-447X

ISSN (Online) 2413-323X

NLM Catalog ID 101673828

DOI: https://doi.org/10.3329/jcamr.v6i1.40780

ORIGINAL ARTICLE OPEN 2 ACCESS

\title{
Self-Medication Practice among Medical Students of a Tertiary Teaching Hospital in Dhaka City
}

\author{
Asma Khan ${ }^{1}$, Afroza Sultana ${ }^{2}$, Benzir Ahammad ${ }^{3}$, Shamsun Nahar $^{4}$, Shafeya Khanam ${ }^{5}$
}

\begin{abstract}
${ }^{1}$ Assistant Professor, Department of Pharmacology and Therapeutics, Shaheed Suhrawardy Medical College, Dhaka, Bangladesh; ${ }^{2}$ Assistant Professor, Department of Pharmacology, Mugda Medical College, Mugda, Dhaka, Bangladesh; ${ }^{3}$ Resident Medical Officer, Trauma Centre, Faridpur Medical College, Faridpur, Bangladesh; ${ }^{4}$ Junior Consultant (Gynaecology \& Obstetrics), Upazila Health Complex, Sonaimuri, Noakhali, Bangladesh; ${ }^{5}$ Associate Professor, Department of Gynaecology \& Obstetrics, Faridpur Medical College, Faridpur, Bangladesh
\end{abstract}

[Received on: 2 January 2018; Reviewed on: 30 March 2018; Accepted on: 19 May 2018; Published on: 1 January 2019]

\section{Abstract}

Background: Self-medication is a common practice worldwide and the irrational use of drugs is a cause of concern. Objective: This present study was designed to assess the rate of selfmedication among the medical students in a tertiary teaching hospital in Dhaka. Methodology: This descriptive cross-sectional study was conducted in the Department of Pharmacology at Shaheed Suhrawardy Medical College, Dhaka, Bangladesh from October to December 2017 for a period of three (03) months. The participants were briefed about the nature of the study; the consent was taken and a pre-tested semi-structured questionnaire was administered to them. The information pertaining to the pattern of self-medication, indications for self-medication and drugs used for self-medication was included in the questionnaire. Result: A total of 303 students were included in this study. The rate of self-medication was $100.0 \%$. A larger number of females were self-medicating $(81.2 \%)$ than males $(75.3 \%)$. The majority of the students self-medicated because of the illness being too trivial for consultation $(43.2 \%)$ and previous experience of illness $(43.2 \%)$. Fever $(73.3 \%)$ and headache $(65 \%)$ are the most common cause of self-medication. Antipyretics were most commonly self-medicated by the participants (98\%). $45.5 \%$ of students told that self-medication is not an acceptable practice. $40 \%$ of the participants opined that selfmedication was a part of self-care. Conclusion: In conclusion self-medication is widely practiced among students of the institute. [Journal of Current and Advance Medical Research 2019;6(1):28-31]

Keywords: Self-medication; practice; medical students

Correspondence: Dr. Asma Khan, Assistant Professor, Department of Pharmacology and Therapeutics, Shaheed Suhrawardy Medical College, Sher-E-Bangla Nagar, Dhaka-1207, Bangladesh; Email: asmakhan1171@ gmail.com; Cell no.: +8801715166825 Cite this article as: Khan A, Sultana A, Ahammad B, Nahar S, Khanam S. Self-Medication Practice among Medical Students of a Tertiary Teaching Hospital in Dhaka City. J Curr Adv Med Res 2019;6(1):28-31

Funding: This study has been performed without any funding from outside else.

Conflict of Interest: There was no conflict of interest to any of the authors.

Contributions to authors: Khan A, Sultana A have contributed in protocol preparation, data collection, data analysis upto the report writing; Ahammad B, Nahar S, Khanam S have written \& revised the manuscript.

Copyright: (02018. Khan et al. Published by Journal of Current and Advance Medical Research. This article is published under the Creative Commons CC BY-NC License (https://creativecommons.org/licenses/by-nc/4.0/). This license permits use, distribution and reproduction in any medium, provided the original work is properly cited, and is not used for commercial purposes. 


\section{Introduction}

Self-care is the primary public health resource in the health care system. It consists of the health activities and health-related decision-making of individuals, families, friends, colleagues at work, and so on ${ }^{1}$. It includes self-medication, non-drug self-treatment, social support in illness, and first aid in everyday life $^{2}$. Self-medication is defined as obtaining and consuming drugs without the advice of a physician either for diagnosis, prescription or surveillance of treatment ${ }^{3}$. This includes acquiring medicines without a prescription, resubmitting old prescriptions to purchase medicines, sharing medicines with relatives or members of one's social circle or using leftover medicines stored at home ${ }^{4}$.

There is a public and professional concern about the irrational use of drugs 5 . The rates are high all over the world; up to $68.0 \%$ in European countries ${ }^{3}$, while much higher in the developing countries ${ }^{4}$ with rates going as high as $92.0 \%$ in the adolescents of Kuwait ${ }^{5}$. The neighboring countries have a prevalence rate of $31.0 \%$ in India $^{6}$ and $59.0 \%$ in $\mathrm{Nepal}^{4}$. Very few studies regarding self-medication have been conducted in Pakistan which have also confirmed high rates of around $51.0 \%^{7}$. It is also alarming that the prevalence rates are on the rise despite efforts to limit this problem ${ }^{8}$.

Self-medication in a country with low literacy rate like Bangladesh is very important, where prescription only medicines are freely available. This may pose serious risks related to inappropriate and irrational personal use of medicines. The widespread availability of prescription only medicines, hence it can be assumed that selfmedication is more widely practiced among health care professionals in Bangladesh more than the general population and medical students are no exceptions. There are many reasons for the increased likelihood of self- medication among medical students. ${ }^{3}$ These students have easy access to information from drug indices, literature, and other medical students to self-diagnose and self-medicate.

Self-medication assumes a special significance among the medical students as they are the future medical practitioners and have a potential role in counseling the patients about the advantages and disadvantages of self-medication. Medical students also differ from the general population because they are well-exposed to the knowledge about diseases and drugs. Therefore, this present study was undertaken to assess the rate of self-medication among the medical students in a tertiary teaching hospital in Dhaka.

\section{Methodology}

This questionnaire based, cross-sectional study was carried out among the medical students of a tertiary care teaching hospital from October to December 2017 for a period of three (03) months. This study was undertaken in the Department of Pharmacology at Shaheed Suhrawardy Medical College, Dhaka, Bangladesh with the approval from the Institutional Ethics Committee. The study population consisted of medical students from second to fourth year, within the age group of 19 to 22 years. Students was selected for the study by a convenient sampling method. The participants were briefed about the nature of the study; the consent was taken and a pre-tested semi-structured questionnaire was administered to them. The information pertaining to the pattern of self-medication, indications for self-medication and drugs used for self-medication was included in the questionnaire. The investigators were present when the respondents required assistance. For the purpose of the study, certain medical terms were explained to the first-year students, including dysmenorrhea, antipyretics and analgesics. The returned questionnaires were checked for completeness of data. The data obtained from the completed questionnaires was analyzed in the computer by using SPSS version 20.0. The qualitative data were expressed as frequency and percentage and the quantitative data were expressed as mean and standard deviation.

\section{Result}

A total of 303 students voluntarily participated in this study, of whom 171(56.4\%) were female and 132(43.6\%) were male. The mean age of the student was 20.6. Among these 303 students, 97(32\%), $93(30.7 \%)$ and $113(49.8 \%)$ were studying in second year, third year and fourth year respectively.

Table 1: Socio-demographic characteristics of study population

\begin{tabular}{|l|l|c|c|}
\hline \multicolumn{2}{|l|}{$\begin{array}{l}\text { Socio-demographic } \\
\text { factors }\end{array}$} & Frequency & Percent \\
\hline \multirow{3}{*}{ Gender } & Male & 132 & 43.6 \\
\cline { 2 - 4 } & Female & 171 & 56.4 \\
\hline \multirow{2}{*}{$\begin{array}{l}\text { Gge } \\
\text { Group }\end{array}$} & $19-20$ & 152 & 50.2 \\
\cline { 2 - 4 } $\begin{array}{l}\text { Year of } \\
\text { study }\end{array}$ & $21-22$ & 151 & 49.8 \\
\cline { 2 - 4 } & Second year & 97 & 32 \\
\cline { 2 - 4 } & Third year & 93 & 30.7 \\
\cline { 2 - 4 } & Fourth year & 113 & 37 \\
\hline
\end{tabular}

All the participants those were participated in this study said that they practiced self-medication. All 
the variables were denoted in multiple response questions (Table 1).

\section{Reasons for self-medication}

The most common factors that led to it were prior experience of illness $(43.2 \% \mathrm{n}=131)$ and selfperception of illness too minor for consultation $(43.2 \% \mathrm{n}=131)$ (Table 2).

Table 2: Reasons among the respondents of selfmedication with medicine $(n=303)$

\begin{tabular}{|l|c|c|}
\hline Factor & Frequency & Percent \\
\hline $\begin{array}{l}\text { Illness too minor for } \\
\text { consultation }\end{array}$ & 131 & 43.2 \\
\hline Prior illness experience & 131 & 43.2 \\
\hline $\begin{array}{l}\text { Self-confidence regarding } \\
\text { awareness about medicine }\end{array}$ & 65 & 21.5 \\
\hline Quick relief excessive & 14 & 4.6 \\
\hline $\begin{array}{l}\text { Avoiding } \\
\text { crowds in hospital }\end{array}$ & 4.6 \\
\hline
\end{tabular}

Complaints among the respondents of selfmedication with medicine

The most common symptoms that led students to indulge in self-medication were fever $(73.3 \%)$, headache $(65 \%)$, running nose $(33 \%)$, cough $(29 \%)$, diarrhea $(27.1 \%)$ and pain in lower abdomen $(20.5 \%)$ (Table 3).

Table 3: Complaints among the respondents of self-medication with medicine $(n=303)$

\begin{tabular}{|l|c|c|}
\hline $\begin{array}{l}\text { Complaints among the } \\
\text { respondents of self- } \\
\text { medication }\end{array}$ & Frequency & Percent \\
\hline Fever & 222 & 73.3 \\
\hline Headache & 197 & 65.0 \\
\hline Running Nose & 100 & 33.0 \\
\hline Cough & 88 & 29.0 \\
\hline Diarrhoea & 82 & 27.1 \\
\hline Lower Abdomen Pain & 62 & 20.5 \\
\hline Heart Burn & 56 & 18.5 \\
\hline Food Poisoning & 42 & 13.9 \\
\hline
\end{tabular}

Name of the drug used for self-medication

Painkillers $(88.1 \%)$, fever relieving medication (65.0\%), anti-allergic (43.9\%) and antibiotics (35.0\%) were among the most commonly used drugs. Therefore, from this result it was very clear that the NSAIDs were the most common drugs which were consumed by the medical students as self-medicated drugs (Table 4).
Table 4: Name of the drug used for selfmedication

\begin{tabular}{|l|c|c|}
\hline $\begin{array}{l}\text { Drug Used For } \\
\text { Self-Medication }\end{array}$ & Frequency & Percent \\
\hline Paracetamol & 197 & 65.0 \\
\hline Anti-allergic & 133 & 43.9 \\
\hline Painkiller & 267 & 88.1 \\
\hline Antibiotic & 106 & 35.0 \\
\hline
\end{tabular}

Perceptions of respondents about selfmedication

Table 5 showed perceptions of respondents about self-medication. Here perceptions of majority of the respondents were not acceptable practice which was $138(45.5 \%)$ respondents and minority was good practice which was $43(14.2 \%)$ respondents.

Table 5: Perceptions of respondents about selfmedication

\begin{tabular}{|l|c|c|}
\hline Perceptions & Frequency & Percent \\
\hline Not acceptable practice & 138 & 45.5 \\
\hline Acceptable practice & 122 & 40.3 \\
\hline Good practice & 43 & 14.2 \\
\hline
\end{tabular}

\section{Discussion}

Self-medication is becoming an increasingly important area within healthcare ${ }^{9-10}$ and this study has shown that it is even more prevalent among medical students. This study has found a rate of self-medication in $100.0 \%$ among the medical students in. It is also noted that a high level of education and professional status are predictive factors for self-medication ${ }^{3}$. This is almost similar to the findings in a study ${ }^{6}$ but is higher than the findings $(60 \%)$ in the study conducted by James and colleagues ${ }^{5}$.

In this study it was found that more female students (56.4\%) practice self-medication than male students (43.6\%). This similar to a previous study conducted among medical students, which showed a greater rate among female students $(45.0 \%)$ than male students $(44.0 \%)^{11}$. This present study has denoted that the most common factors that led to it were "prior experience of illness" (43.2\%) and selfperception of "illness too minor for consultation" (43.2\%) which is in concordance with other studies that reported the reasons as mild illness $(40.0 \%)$ and shortage of time to consult a doctor $(32 \%)^{11}$. The next common reason for self-medication in this study among medical students is their confidence in self-diagnosis $(21.5 \%)$, which is unique to this 
study group. Misplaced confidence can lead to inappropriate self-medication and can expose the participants to all the risks associated with inappropriate use of medications ${ }^{3}$.

With respect to indications, results were similar to those found in a previous study ${ }^{3}$. It has been also found that medical student's self-medicate for unusual reasons like sports injuries, hangovers, exam stress and recreational drug use which may not be common in the general public. In this study it has been noticed that the classes of drugs that are commonly used are antipyretics $(71.0 \%)$, analgesics (65.0\%), antihistamines (37.0\%) and antibiotics $(34.0 \%)$. This is similar to studies done earlier which showed antipyretics $(43.0 \%)$, analgesics (81\%), antibiotics (6.0\%) and antihistamines $(13.0 \%)$ were commonly used ${ }^{3}$. In other studies, it was found that medical students used more types of antibiotics compared to the non-medical students which may be because of their knowledge about antibiotics ${ }^{7}$. However, it has been found that $11(5.5 \%)$ of the medical students are not afraid of using drugs with potentially harmful adverse effects and potential for addiction and abuse like sleeping pills $(2.0 \%)$, steroids $(2.0 \%)$ and stimulants $(1.5 \%)$. These drugs may not be as easily available to the general population as they are medical students who can obtain them by virtue of their profession. Previous studies have reported a higher use of antimicrobials when the study participant is a healthcare professional ${ }^{3}$.

Despite studying in detail about all these drug reactions, $32.6 \%$ of the students were unaware of the adverse effects of the drugs they used for self-medication. In addition to this, $5.4 \%$ of the study group reported experiencing adverse effects for which they either consulted a doctor or stopped the medication.

The study group cited their source of information for self- medication in most cases as textbooks $(39.0 \%)$ and seniors or classmates $(38 \%)$; this is similar to other studies, which has been showed medical students use their academic medical knowledge during self-medication ${ }^{7}$.

There are some limitations of this study like absence of a comparative group are, such as students from another field; the small sample size and the absence of interventions, like providing information regarding hazards of self-medication.

\section{Conclusion}

This study shows that self-medication is widely practiced among students of the institute. This descriptive study has found that self-medication is very common among medical students, facilitated by the easy availability of drugs, and information from textbooks/seniors. A significant number of students are unaware of the adverse effects of the medication that they themselves take and suggest to others. Potential problems of self- medication should be emphasized to the students to minimize this risk.

\section{References}

1. Chowdhury N, Matin F, Chowdhury SF. Medication taking behavior of students attending a private university in Bangladesh. Int J Adolesc Med Health 2009;21(3);361-370

2. Islam MS. Self-medications among higher educated population in Bangladesh: an email-based exploratory study. Internet J Health 2007;5(2):20-25

3. Alam N, Saffoon N, Uddin R. Self-medication among medical and pharmacy students in Bangladesh. BMC research notes. 2015;8(1):763

4. Biswas M, Roy MN, Manik MI, Hossain MS, Tapu ST, Moniruzzaman M, Sultana S. Self medicated antibiotics in Bangladesh: a cross-sectional health survey conducted in the Rajshahi City. BMC public health. 2014;14(1):847

5. James H, Handu SS, Khalid AJ, Khaja A, Otoom S, Sequeira RP. Evaluation of the knowledge, attitude and practice of self-medication among first-year medical students. Med Princ Pract 2006;15:270-275

6. Badiger S, Kundapur R, Jain A, Kumar A, Pattanshetty S, Thakolkaran N, Bhat N, Ullal N. Self-medication patterns among medical students in South India. The Australasian medical journal. 2012;5(4):217

7. Chowdhury N, Haque A, Aysha F. Investigation into selfmedication of drugs for primary and adjunct therapy in psychiatric diseases among students in chittagong city of bangladesh: a comparison between medical and nonmedical students. Indian journal of psychological medicine. 2012;34(4):313

8. Ali SE, Ibrahim MI, Palaian S. Medication storage and selfmedication behaviour amongst female students in Malaysia. Pharmacy Practice. 2010;8(4):12-16

9. Ilhan MN, Durukan E, Ilhan SÖ, Aksakal FN, Özkan S, Bumin MA. Self-medication with antibiotics: questionnaire survey among primary care center attendants. Pharmacoepidemiology and drug safety. 2009;18(12):1150-7 10. Jakaria M, Hasant A, Tarek MI, Islam MZ, Zaman R, Parvez M, Chowdhury TA, Hasan MI, Sayeed MA, Ali MH. Evaluation of Self Medication among Students from Different Universities in Chittagong, Bangladesh. Journal of Medicine. 2017;18(1):15-20

11. Haque S. Association between Self-Medication Behavior and Adherence among Medical Students in Dhaka, Bangladesh. Asian Journal of Pharmaceutics (AJP): Free full text articles from Asian J Pharm. 2017;11(02):S346-S352 